\title{
Expression of serum miR-27b and miR-451 in patients with congenital heart disease associated pulmonary artery hypertension and risk factor analysis
}

\author{
LEIWANG LONG ${ }^{1}$, YUNBIN XIAO $^{2}$, XIAOCHENG YIN ${ }^{3}$, SHUNLI GAO $^{1}$, LINGZHI ZHOU $^{1}$ and HUI LIU ${ }^{1}$ \\ ${ }^{1}$ Paediatric Intensive Care Unit, The First Affiliated Hospital of the University of South China, Hengyang, Hunan 421000; \\ ${ }^{2}$ Department of Cardiology, Hunan Children's Hospital, Changsha, Hunan 410007; ${ }^{3}$ Department of Pediatrics, \\ The First Affiliated Hospital of the University of South China, Hengyang, Hunan 421000, P.R. China
}

Received September 24, 2019; Accepted May 12, 2020

DOI: $10.3892 /$ etm.2020.9042

\begin{abstract}
This study investigated expression of serum miR-27b and miR-451 in patients with congenital heart disease associated pulmonary arterial hypertension (CHD-PAH), and analyzed the risk factors of CHD-PAH. A total of 114 patients with CHD admitted to the First Affiliated Hospital of the University of South China were recruited and allocated into a study group (61 patients with PAH) and a control group (53 patients without PAH). Reverse transcription-polymerase chain reaction (RT-PCR) was employed for the qualification of serum miR-27b and miR-451, and an automatic biochemical analyzer was used for the measurement of biochemical indexes in peripheral blood, and enzyme-linked immunosorbent assay (ELISA) for the detection of serum brain natriuretic peptide (BNP) and asymmetric dimethylarginine (ADMA). The patients with CHD-PAH showed higher serum miR-27b, BNP and ADMA but lower miR-451 than the controls. Serum miR-27b was positively correlated with mean pulmonary artery pressure (mPAP), BNP and ADMA, whereas serum miR-451 was negatively correlated with them. The combined detection of miR-27b and miR-451 was more valuable than a single detection in the diagnosis of CHD-PAH. Logistic regression analysis showed that ADMA, miR-27b, miR-451 and ventricular septal defect (VSD) were independent risk factors for CHD-PAH. In conclusion, miR-27b is highly expressed and miR-451 and the expression is low in patients with CHD-PAH. miR-27b and miR-451 are significantly correlated with BNP, ADMA, and the severity of the disease.
\end{abstract}

Correspondence to: Dr Leiwang Long, Paediatric Intensive Care Unit, The First Affiliated Hospital of the University of South China, 69 Chuanshan Road, Hengyang, Hunan 421000, P.R. China E-mail: longleiwang@qq.com

Key words: miR-27b, miR-451, congenital heart disease associated pulmonary arterial hypertension, risk factor analysis, serum, diagnosis
The combination of miR-27b and miR-451 has high diagnostic value and can be used as a biomarker for the diagnosis and assessment of CHD-PAH. CHD-PAH is common in children with $\mathrm{CHD}$, which poses a serious threat to the life and safety. At present, there are no effective methods for its early diagnosis and treatment. MicroRNAs (miRNAs, miRs) have been found to be closely related to the pathogenesis of CHD-PAH. In this study, miR-27b and miR-451 with differential expression in CHD-PAH were evaluated, and it was found that they were of great significance in the diagnosis and assessment of CHD-PAH.

\section{Introduction}

Pulmonary arterial hypertension (PAH) is a disease mainly characterized by pulmonary vascular remodeling and elevated pulmonary arterial pressure (PAP) (1). The abnormal cardiac structure in patients with congenital heart disease (CHD), a common cardiac disease in clinical practice, may cause aggravation of the cardiac load, resulting in elevated blood flow in the pulmonary circulation and increased pulmonary pressure, leading to the development of PAH $(2,3)$. Congenital heart disease associated pulmonary arterial hypertension (CHD-PAH) is one of the most common types of PAH. Once PAH occurs in CHD patients, it will further increase the blood flow to the heart and aggravate the cardiac load, thus seriously affecting the quality of life of patients and even leading to cardiac failure or death $(4,5)$. Moreover, since there are no typical clinical symptoms in early CHD-PAH, seeking a specific marker is of great significance for its diagnosis and treatment.

MicroRNAs (miRNAs, miRs) have been reported to play an important role in the pathogenesis of $\mathrm{PAH}$, which regulate not only the proliferation and apoptosis of vascular endothelial cells (VECs), but also angiogenesis, proliferation and apoptosis of vascular smooth muscle cells (VSMCs) $(6,7)$. miR-27b is a miRNA differentially expressed in CHD-PAH. Previous studies have only detected the expression of miR-27b, its clinical significance and mechanism in CHD-PAH has rarely been discussed (8). miR-451 is down-regulated in the lungs of PAH animal models, and its reduction in serum may affect the 
function of VECs or VSMCs (9). There is research highlighting the role of miR-451 in the development of heart disease (10), which leads us to speculate that miR-451 is also closely related to the pathogenesis of CHD-PAH.

This study analyzed the expressions and clinical significance of miR-27b and miR-451 in CHD-PAH and explored its risk factors, in order to provide new targets and more theoretical basis for the diagnosis and treatment of CHD-PAH.

\section{Patients and methods}

General data. A total of 114 patients with CHD admitted to the First Affiliated Hospital of the University of South China (Hengyang, China) from July 2016 to January 2019 were prospectively analyzed, including 63 males and 51 females, with an average age of $12.29 \pm 1.15$ years. They were allocated into a study group (61 patients with $\mathrm{PAH}$ ) and a control group (53 patients without $\mathrm{PAH}$ ). Inclusion criteria: All patients enrolled were diagnosed with CHD, and those in the study group were diagnosed with CHD-PAH by PAP measurements. Exclusion criteria: Patients with other malignant tumors, severe immune system diseases, liver and kidney dysfunction, or lung diseases. The study was approved by the Ethics Committee of The First Affiliated Hospital of the University of South China. Patients who participated in this research had complete clinical data. The patients and their families agreed to participate in the experiment and signed written informed consents were obtained from the parents of the child patients.

Index detection. Fasting venous blood $(5 \mathrm{ml})$ collected from the patients in the morning following admission was added with heparin for anticoagulation, then centrifuged at $1,500 \mathrm{xg}$ for $5 \mathrm{~min}$ at $4^{\circ} \mathrm{C}$. The serum was obtained for testing.

Detection of miR-27b and miR-451 by reverse transcription-polymerase chain reaction (RT-PCR). Fasting venous blood $(5 \mathrm{ml})$ collected from all the patients was centrifuged at $1,500 \mathrm{x} \mathrm{g}$ for $10 \mathrm{~min}$ at $4^{\circ} \mathrm{C}$, and the supernatant was obtained. TRIzol reagent was added to serum to extract total RNA, and the purity and concentration of the RNAs were tested by an ultraviolet spectrophotometer. The total RNAs were reverse transcribed using SYBR-Green Real-time PCR Master Mix in strict accordance with the instruction of the kit. Then PCR amplification was carried out with the PrimeScript RT Master Mix Kit (Takara Bio). Amplification system: $10 \mu \mathrm{l} \mathrm{SYBR}$ qPCR Mix, $0.8 \mu 1$ each upstream and downstream primers, $2 \mu \mathrm{l}$ cDNA product, $0.4 \mu 1$ 50X ROX reference dye, made up to $20 \mu \mathrm{l}$ with $\mathrm{RNase}$-free water. PCR reaction condition: Pre-denaturation at $95^{\circ} \mathrm{C}$ for $35 \mathrm{sec}$, followed by 40 cycles of denaturation at $94^{\circ} \mathrm{C}$ for $30 \mathrm{sec}$, annealing at $60^{\circ} \mathrm{C}$ for $40 \mathrm{sec}$, and extension at $72^{\circ} \mathrm{C}$ for $30 \mathrm{sec}$. The primers were all synthesized at Sangon Bioengineering Co., Ltd. (Table I). U6 was used as an internal reference and the relative mRNA expression was calculated by $2^{-\Delta \Delta \mathrm{Ct}}$.

Detection of other biochemical indexes. The levels of total cholesterol (TC), triglyceride (TG), alanine transaminase (ALT), blood urea nitrogen (BUN) and serum creatinine (SCr) were measured by the DXC800 automatic biochemical analyzer (Beckman Coulter). The levels of brain natriuretic peptide (BNP) and asymmetric dimethylarginine (ADMA) were detected by enzyme-linked immunosorbent assay
(ELISA). The kits were all purchased from Wuhan MSK Biotechnology Co., Ltd. and the operation was carried out strictly in accordance with the instructions of the kits.

Measurement of MPAP by right heart catheterization. Right heart catheterization (RHC) is the gold standard for diagnosis of CHD-PAH (11). The patients underwent femoral venous puncture after local anesthesia. Next, a 6-F vascular sheath was inserted, and heparin was injected intravenously for anticoagulation. Right heart catheter was inserted into right ventricle and pulmonary artery through the vascular sheath to measure the mean pulmonary artery pressure (mPAP).

Statistical analysis. In this study, SPSS 18.0 [Boyi Zhixun (Beijing) Information Technology Co., Ltd.] was used to carry out statistical analysis. Chi-square test was employed for counting data and mean \pm standard deviation for measurement data. The comparison between the two groups was conducted by t-test. Pearson was used for correlation analysis and receiver operating characteristics (ROC) for assessment of the predictive value of single and combined miR-27b and miR-451 for CHD-PAH. Multivariate Logistic regression was performed to analyze the risk factors of CHD-PAH. A value of $\mathrm{P}<0.05$ was considered statistically significant.

\section{Results}

General data. There was no significant difference in sex, age and body mass index (BMI) between the two groups (P>0.05) (Table II).

Expression of serum miR-27b and $m i R-451$. Expression of serum miR-27b and miR-451 in the study group was $1.32 \pm 0.28$ and $0.73 \pm 0.24$, respectively, while those in the control group $1.03 \pm 0.13$ and $0.95 \pm 0.18$, respectively. Therefore, the expression of serum miR-27 in the study group was significantly higher than that in the control group, and the expression of miR-451 was significantly lower than that in the control group $(\mathrm{P}<0.05)$ (Fig. 1).

Predictive value of BNP and ADMA in CHD-PAH. The sensitivity, specificity, and area under the curve (AUC) of serum BNP in predicting CHD-PAH were 96.23\%, 88.52\% and 0.971, respectively, and those of ADMA were $94.34 \%, 78.69 \%$ and 0.959 , both of which were of high value. Therefore, BNP and ADMA were selected to carry out correlation analysis with miR-27b and miR-451 to evaluate the correlation between miR-27b, miR-451 and CHD-PAH (Fig. 2).

Correlation of serum miR-27b and miR-451 with $\mathrm{mPAP}$, $B N P$ and ADMA. Serum miR-27b was positively correlated with mPAP, BNP and ADMA ( $\mathrm{r}=0.690, \mathrm{P}<0.05 ; \mathrm{r}=0.688$, $\mathrm{P}<0.05 ; \mathrm{r}=0.658, \mathrm{P}<0.05)$, and serum miR-451 was negatively correlated with mPAP, BNP and ADMA ( $\mathrm{r}=-0.736, \mathrm{P}<0.05$; $\mathrm{r}=-0.761, \mathrm{P}<0.05 ; \mathrm{R}=-0.730, \mathrm{P}<0.05$ ) (Fig. 3).

Predictive value of single and combined miR-27b and miR-451 in CHD-PAH. The sensitivity, specificity and AUC of serum miR-27b in CHD-PAH prediction were $73.58 \%$, $70.49 \%$ and 0.757 , respectively, while those of miR-451 were 
Table I. Related primer sequences.

\begin{tabular}{lll}
\hline Gene & \multicolumn{1}{c}{ Upstream primers } & Downstream primers \\
\hline miR-27b & 5'-TTCACAGTGGCTAAGT-3' & 5'-CAGTGCGTGTCGTGGAGT-3' \\
miR-451 & 5'-CACCTATCGTGGTGAAGTT-3' & 5'-GAATGCACTGCACAATATT-3' \\
U6 & 5'-GCTTCGGCAGCACATATACTAAAAT-3' & 5'-CGCTTCACGAATTTGCGTGTCAT-3'
\end{tabular}

Table II. General data [n (\%)].

\begin{tabular}{|c|c|c|c|c|}
\hline Factor & Study group $(n=61)$ & Control group $(n=53)$ & $\mathrm{t} / \chi^{2}$ value & P-value \\
\hline Sex & & & 0.012 & 0.913 \\
\hline Male & $34(55.74)$ & $29(54.72)$ & & \\
\hline Female & $27(44.26)$ & $24(45.28)$ & & \\
\hline Age, years & & & 0.237 & 0.626 \\
\hline$\leq 12$ & $35(57.38)$ & $28(52.83)$ & & \\
\hline$>12$ & $26(42.62)$ & 25 (47.17) & & \\
\hline $\mathrm{BMI}, \mathrm{kg} / \mathrm{m}^{2}$ & & & 0.058 & 0.809 \\
\hline$\leq 15$ & $29(47.54)$ & $24(45.28)$ & & \\
\hline$>15$ & $32(52.46)$ & $29(54.72)$ & & \\
\hline $\mathrm{TC}(\mathrm{mmol} / \mathrm{l})$ & $4.59 \pm 0.55$ & $4.62 \pm 0.57$ & 0.286 & 0.776 \\
\hline TG (mmol/l) & $0.81 \pm 0.17$ & $0.79 \pm 0.19$ & 0.593 & 0.554 \\
\hline $\operatorname{ALT}(\mathrm{U} / \mathrm{l})$ & $29.11 \pm 4.32$ & $28.16 \pm 5.24$ & 1.061 & 0.291 \\
\hline BUN (mmol/l) & $4.98 \pm 1.14$ & $5.03 \pm 1.22$ & 0.226 & 0.822 \\
\hline $\mathrm{SCr}(\mu \mathrm{mol} / \mathrm{l})$ & $61.64 \pm 9.37$ & $59.96 \pm 10.01$ & 0.925 & 0.357 \\
\hline CHD type & & & 6.705 & 0.035 \\
\hline VSD & $25(40.98)$ & $10(18.87)$ & & \\
\hline ASD & $15(24.59)$ & $23(43.39)$ & & \\
\hline ADS+VSD & $21(34.43)$ & $20(37.74)$ & & \\
\hline mPAP $(\mathrm{mmHg})$ & $43.96 \pm 7.68$ & $15.32 \pm 3.78$ & 24.67 & $<0.001$ \\
\hline $\mathrm{BNP}(\mathrm{pg} / \mathrm{ml})$ & $221.54 \pm 51.46$ & $110.37 \pm 25.94$ & 14.23 & $<0.001$ \\
\hline ADMA $(\mu \mathrm{mol} / \mathrm{l})$ & $0.58 \pm 0.13$ & $0.30 \pm 0.10$ & 12.74 & $<0.001$ \\
\hline
\end{tabular}

TC, total cholesterol; TG, triglyceride; ALT, alanine transaminase; BUN, blood urea nitrogen; SCr, serum creatinine; CHD, congenital heart disease; VSD, ventricular septal defect; mPAP, mean pulmonary artery pressure; BNP, brain natriuretic peptide; ADMA, asymmetric dimethylarginine.
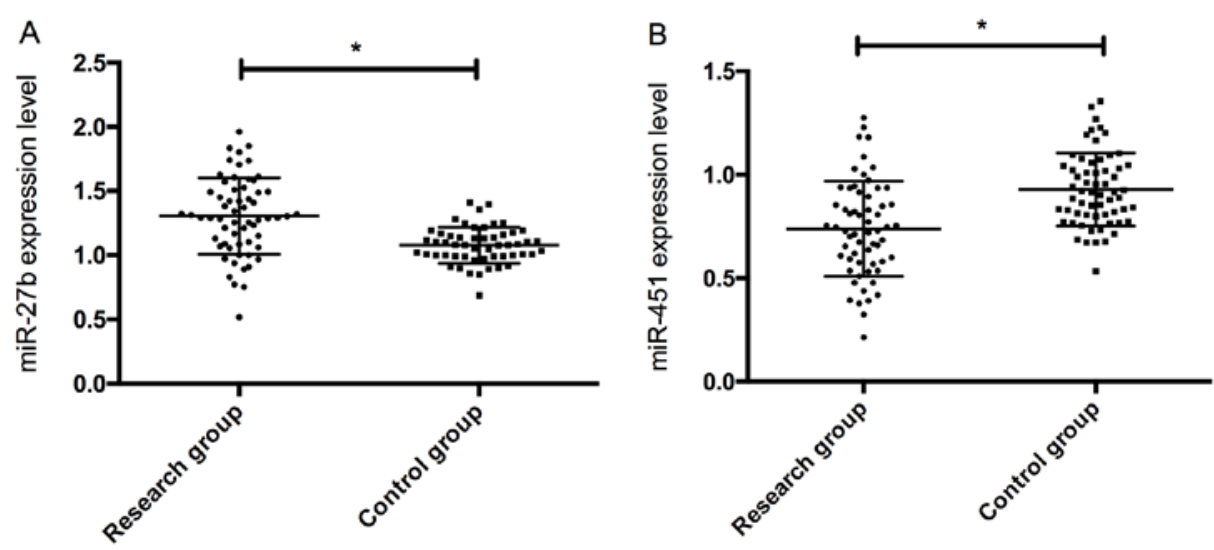

Figure 1. Expression of serum miR-27b and miR-451. (A) Expression of serum miR-27 in the study group was significantly higher than that in the control group. (B) Expression of serum miR-451 in the study group was significantly lower than that in the control group. "P<0.05. 

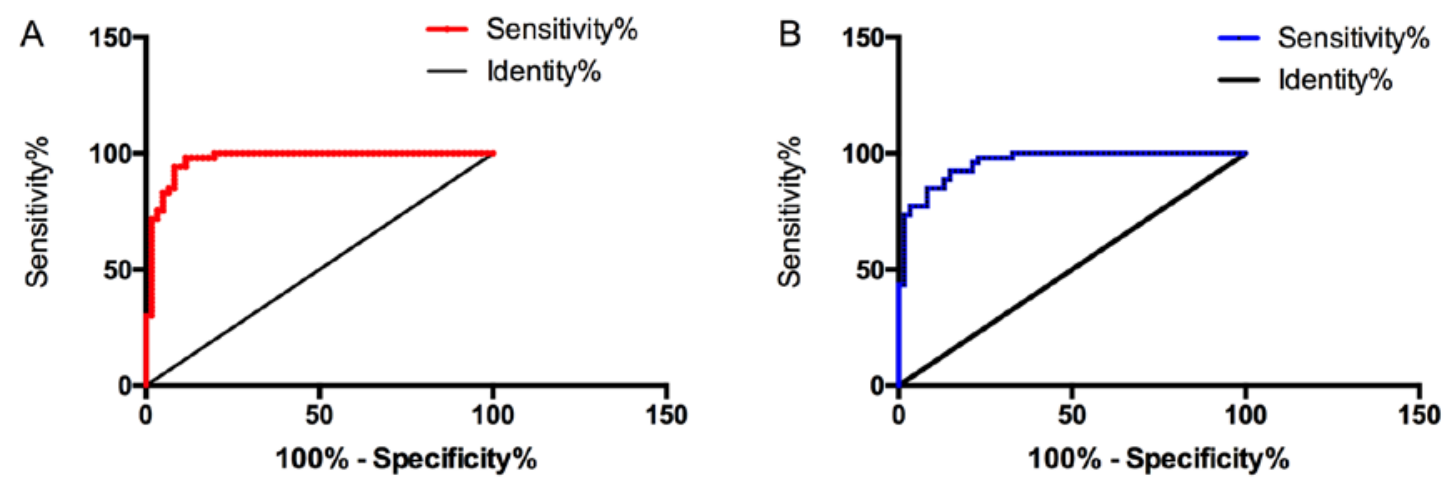

Figure 2. Predictive value of serum BNP and ADMA for CHD-PAH. (A) ROC curve of serum BNP in CHD-PAH prediction. (B) ROC curve of serum ADMA in CHD-PAH prediction. BNP, brain natriuretic peptide; ADMA, asymmetric dimethylarginine; CHD-PAH, congenital heart disease associated pulmonary arterial hypertension; ROC, receiver operating characteristics.
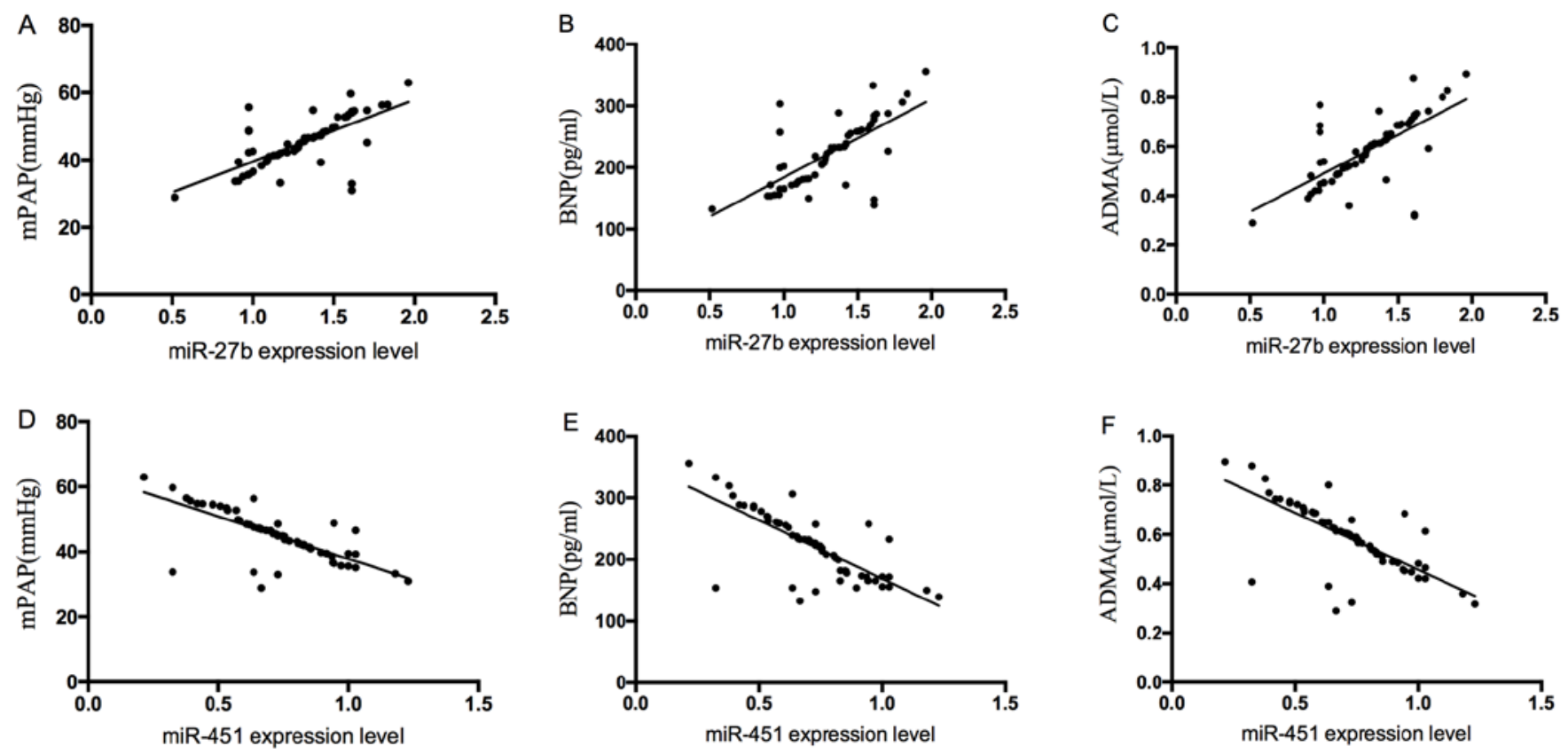

Figure 3. Correlation of serum miR-27b and miR-451 with mPAP, BNP and ADMA. (A) Serum miR-27b was positively correlated with mPAP ( $\mathrm{r}=0.690$, $\mathrm{P}<0.05)$. (B) Serum miR-27b was positively correlated with BNP $(\mathrm{r}=0.688, \mathrm{P}<0.05)$. (C) Serum miR-27b was positively correlated with ADMA ( $\mathrm{r}=0.658$, $\mathrm{P}<0.05)$. (D) Serum miR-451 was negatively correlated with mPAP $(r=-0.736, P<0.05)$. (E) Serum miR-451 was negatively correlated with $B N P(r=-0.761$, $\mathrm{P}<0.05)$. (F) Serum miR-451 was negatively correlated with ADMA $(\mathrm{r}=-0.730, \mathrm{P}<0.05)$. mPAP, mean pulmonary artery pressure; BNP, brain natriuretic peptide; ADMA, asymmetric dimethylarginine.

$71.70 \%, 60.66 \%$ and 0.737 , respectively. Binary Logistic regression analysis was conducted with miR-27b and miR-451 as independent variables. Logistic regression model: Logit $(\mathrm{P})=0.884+1.673 \mathrm{miR}-27 \mathrm{~b}+-2.960 \mathrm{miR}-451$. The AUC, sensitivity and specificity of this model in diagnosing CHD-PAH were $0.840,86.79 \%$ and $68.85 \%$, respectively. The combined detection of miR-27b and miR- 451 was more valuable in the diagnosis of CHD-PAH than the single detection (Fig. 4).

Risk factors of PAH in patients with CHD. Factors with differences between CHD and CHD-PAH patients were classified as independent variables, including BNP, ADMA, ventricular septal defect (VSD), miR-27b and miR-451. After assignments (Table III), logistic regression was used to analyze whether these factors were independent risk factors of
Table III. Assignments.

\begin{tabular}{ll}
\hline Factor & \multicolumn{1}{c}{ Assignment } \\
\hline BNP & $\begin{array}{l}\text { The data is a continuous variable and } \\
\text { analyzed with raw data. } \\
\text { The data is a continuous variable and } \\
\text { analyzed with raw data. }\end{array}$ \\
ADMA & $\begin{array}{l}\text { Yes =1, No =2 } \\
\text { The data is a continuous variable and } \\
\text { analyzed with raw data. }\end{array}$ \\
miR-27b & $\begin{array}{l}\text { The data is a continuous variable and } \\
\text { analyzed with raw data. }\end{array}$ \\
miR-451 &
\end{tabular}

BNP, brain natriuretic peptide; ADMA, asymmetric dimethylarginine; VSD, ventricular septal defect. 

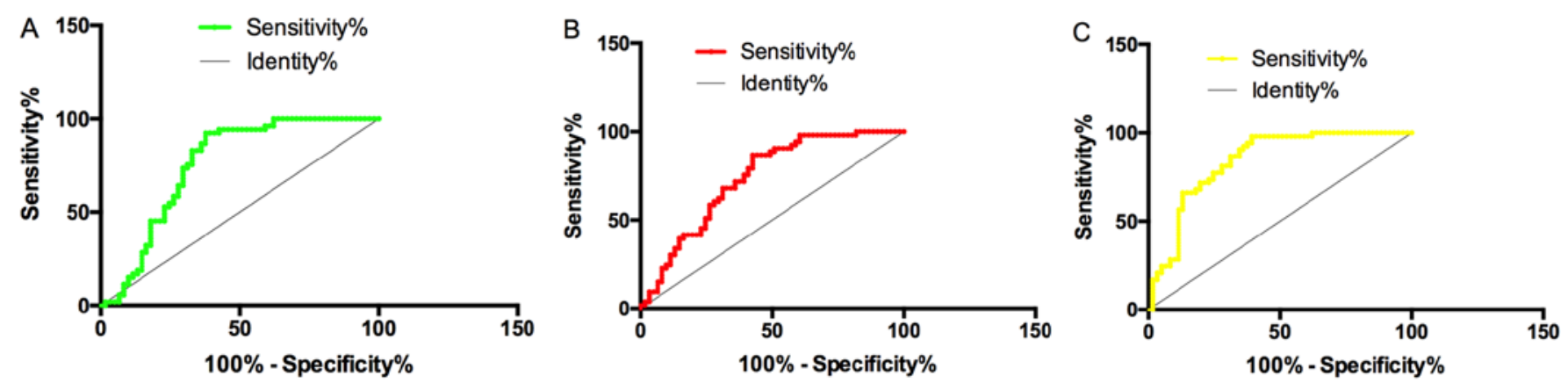

Figure 4. Predictive values of single and combined miR-27b and miR-451 for CHD-PAH. (A) Sensitivity, specificity and AUC of serum miR-27b in CHD-PAH prediction were $73.58 \%, 70.49 \%$ and 0.757 , respectively. (B) Sensitivity, specificity and AUC of miR-451 in CHD-PAH prediction were $71.70 \%, 60.66 \%$ and 0.737, respectively. (C) AUC, sensitivity and specificity of combined detection of miR-27b and miR-451 in CHD-PAH prediction were $0.840,86.79 \%$ and $68.85 \%$, respectively. CHD-PAH, congenital heart disease associated pulmonary arterial hypertension.

Table IV. Multivariate analysis.

\begin{tabular}{lcccccr}
\hline Factor & $\beta$ & SE & Wald & OR & $95 \%$ CI & P-value \\
\hline BNP & 3.167 & 0.649 & 2.227 & 6.097 & $3.124-5.011$ & $<0.01$ \\
ADMA & 2.876 & 0.422 & 1.970 & 2.286 & $1.019-4.211$ & $<0.01$ \\
VSD & 3.146 & 0.605 & 2.191 & 2.578 & $1.116-4.778$ & $<0.01$ \\
miR-27b & 3.455 & 0.729 & 2.554 & 3.783 & $1.226-5.103$ & $<0.01$ \\
miR-451 & 3.145 & 0.608 & 2.139 & 2.686 & $1.189-4.856$ & $<0.01$ \\
\hline
\end{tabular}

BNP, brain natriuretic peptide; ADMA, asymmetric dimethylarginine; VSD, ventricular septal defect.

COPD-PH. The results showed that increased BNP, ADMA, miR-27b, decreased miR-451, as well as the presence of VSD were independent risk factors of CHD-PAH (Table IV).

\section{Discussion}

PAH, a common complication of CHD, is one of the main causes of death in patients with CHD (12). PAH-CHD is a disease with high incidence posing a serious threat to the physical and mental health of the majority of children (13). As a highly stable single-stranded small molecule, miRNA has been widely studied in recent years and it has been found that the differential expression of several miRNAs may be closely related to the pathogenesis of PAH $(14,15)$.

In this study, the expression and clinical significance of miR-27b and miR-451 in PAH-CHD were explored. Some scholars proved that miR-27b is differentially expressed in PAH-CHD using gene chip technology (16). Moreover, miR-451 is found to be closely related to the pathogenesis of PAH (17), but its clinical significance in CHD-PAH has not been not discussed yet. In this study, expressions of serum miR-27b and miR-451 in patients with PAH and CHD-PAH were detected. It turned out that serum miR-27b in patients with CHD-PAH was significantly higher than that in patients with PAH, and miR-451 was significantly lower than that in patients with PAH. Previously scholars also stated that miR-27b is highly expressed in PAH-CHD by screening the differential expression of miRNAs (18). Animal experiments showed that miR-451 is down-regulated in PH rats, which was consistent with our conclusion (19). Subsequently, in order to explore the clinical significance of miR-27b and miR-451 in CHA-PAH, we conducted analysis on the correlation of miR-27b and miR-451 with mPAP, BNP and ADMA. BNP is one of the most sensitive indicators for predicting heart failure clinically. Damage of myocardial cells increases the synthesis of BNP rapidly and greatly, which can better reflect the cardiac function (20). ADMA, a newly discovered inhibitory cytokine, is found to inhibit the release of NO by binding with the active site of NOS, and it is considered to be one of the predictors of PAH (21). MPAP is the most direct indicator to reflect PAP and the severity of PAH (22). This study showed that serum miR-27b was positively correlated with mPAP, BNP and ADMA, and serum miR-451 was negatively correlated with them, which suggested that both miR-27b and miR-451 might be used as evaluation indicators of CHD-PAH.

At present, RHC is the gold standard for the diagnosis of CHD-PAH (23), but it is still of great significance to seek effective noninvasive biomarkers for clinical practice. Therefore, in this study, we analyzed the diagnostic value of single and combined miR-27b and miR-451 in CHD-PAH diagnosis. The results showed that the AUC of miR-27b and miR-451 was 0.757 and 0.737 , respectively, indicating their low predictive value. However, the AUC of the combined detection increased to 0.840 , which suggested that miR-27b and miR-451 may be used as reference indicators for the diagnosis of CHD-PAH. A study noted that the AUC of miR-451 in PAH diagnosis was $\sim 0.710$, which was similar to our conclusion (24). However, the predictive value of miR-27b for CHD-PAH has been poorly explored. In addition for timely diagnosis and treatment, it is equally important to identify the 
risk factors to effectively prevent CHD-PAH. Therefore, the etiologic factors of CHD-PAH were also analyzed in this study. Increased BNP, ADMA and miR-27b, and decreased miR-451 as well as the presence of VSD were shown as independent risk factors of CHD-PAH. A previous study (25) indicated that the untimely repair of severe VSD results in irreversible remodeling of pulmonary vessels, and spontaneous PAH may occur if surgery is performed at this time. Besides, another study showed that VSD is more likely to cause PAH due to its special hemodynamics (26). At present, there is no related research reported on the mechanism of miR-27b and miR-451 in CHD-PAH. Therefore, the conclusion that miR-27b and miR-451 are independent risk factors of CHA-PAH remains to be further investigated by follow-up research.

To sum up, miR-27b is highly expressed and miR-451 expression is low in patients with CHD-PAH. miR-27b and miR-451 are significantly correlated with the severity of the disease, BNP and ADMA. The combination of miR-27b and miR-451 has a high diagnostic value and can be used as a biological marker for diagnosis and assessment of CHD-PAH. However, we failed to access enough literature to explain the mechanism of miR-27b and miR-451 in CHD-PAH, which is to be further elaborated by in vivo and in vitro experiments. Analysis of risk factors of CHD-PAH was not comprehensive. Therefore, further study is required on the risk factors of CHD-PAH.

\section{Acknowledgements}

Not applicable.

\section{Funding}

No funding was received.

\section{Availability of data and materials}

The datasets used and/or analyzed during the present study are available from the corresponding author on reasonable request.

\section{Authors' contributions}

LL designed the study. YX was responsible for the detection of the indices. XY contributed with new reagents and analytic tools. SG analyzed the data. LZ and HL were responsible for the measurement of mPAP by right heart catheterization and wrote the manuscript. All authors read and approved the final version of the manuscript.

\section{Ethics approval and consent to participate}

The study was approved by the Ethics Committee of The First Affiliated Hospital of the University of South China (Hengyang, China). Patients who participated in this research had complete clinical data. Signed written informed consents were obtained from the parents of the child patients.

\section{Patient consent for publication}

Not applicable.

\section{Competing interests}

The authors declare that they have no competing interests.

\section{References}

1. Chew JD, Loyd JE and Austin ED: The genetics of pulmonary arterial hypertension. Semin Respir Crit Care Med 38: 585-595, 2017.

2. van der Feen DE, Bartelds B, de Boer RA and Berger RM: Pulmonary arterial hypertension in congenital heart disease: Translational opportunities to study the reversibility of pulmonary vascular disease. Eur Heart J 38: 2034-2041, 2017.

3. Roberts KE, McElroy JJ, Wong WP, Yen E, Widlitz A, Barst RJ, Knowles JA and Morse JH: BMPR 2 mutations in pulmonary arterial hypertension with congenital heart disease. Eur Respir J 24: 371-374, 2004.

4. Sun ML, Cheng CY, Wu DC, Zhao QH, Liu QQ, Jiang R, Jiang $X$ and Jing ZC: Long-term survival of patients with repaired congenital heart disease associated pulmonary arterial hypertension (CHD-PAH) in the modern management era. Eur Heart J 34 (Suppl 1): P287, 2013.

5. Sun ML, Cheng CY, Wu DC, Zhang R, Zhang X, Xu XQ, Sun K, Zhao QH, Wang X-J, Jiang R, et al: Survival of patients with repaired CHD-PAH in the modern management era. J Am Coll Cardiol 63: A1484, 2014.

6. Boucherat O, Potus F and Bonnet S: microRNA and pulmonary hypertension. Adv Exp Med Biol 888: 237-252, 2015.

7. Grant JS: The role of microRNA in the development of pulmonary arterial hypertension: Studies in cell culture and animal models. University of Glasgow, p263, 2014.

8. Hailong D and Yin XL: GW25-e2158. The changes of plasma miR-18a, miR-27b, miR-130a, miR-204 in patients with pulmonary arterial hypertension due to congenital heart disease. J Am Coll Cardiol 64 (Suppl 16): C190-C190, 2014.

9. Caruso P, Dempsie Y, Stevens HC, McDonald RA, Long L, Lu R, White K, Mair KM, McClure JD, Southwood M, et al: A role for miR-145 in pulmonary arterial hypertension: Evidence from mouse models and patient samples. Circ Res 111: 290-300, 2012.

10. Wang X, Zhu H, Zhang X, Liu Y, Chen J, Medvedovic M, Li H, Weiss MJ, Ren X and Fan GC: Loss of the miR-144/451 cluster impairs ischaemic preconditioning-mediated cardioprotection by targeting Rac-1. Cardiovasc Res 94: 379-390, 2012.

11. Grymuza M, Małaczyńska-Rajpold K, Jankiewicz S, Siniawski A, Grygier M, Mitkowski P, Kałużna-Oleksy M, Lesiak M, Mularek-Kubzdela T and Araszkiewicz A: Right heart catheterization procedures in patients with suspicion of pulmonary hypertension - experiences of a tertiary center. Postepy Kardiol Interwencyjnej 13: 295-301, 2017.

12. Stephan R, Ghofrani H, Beghetti M, Ivy D, Fritsch A, Weimann G, Saleh S, Apitz C and Frey R: Riociguat for pulmonary arterial hypertension (PAH) associated with congenital heart disease (CHD): A subgroup analysis from the PATENT studies. BMC Pharmacol Toxicol 16 (Suppl 1): A79, 2015.

13. Chen IC and Dai ZK: Insight into pulmonary arterial hypertension associated with congenital heart disease (PAH-CHD): Classification and pharmacological management from a pediatric cardiological point of view. Acta Cardiol Sin 31: 507-515, 2015.

14. Chen W and Li S: Circulating microRNA as a novel biomarker for pulmonary arterial hypertension due to congenital heart disease. Pediatr Cardiol 38: 86-94, 2017.

15. Zhao H, Guo Y, Sun Y, Zhang N and Wang X: miR-181a/b-5p ameliorates inflammatory response in monocrotaline-induced pulmonary arterial hypertension by targeting endocan. J Cell Physiol 235: 4422-4433, 2020.

16. Thum T, Galuppo P, Wolf C, Fiedler J, Kneitz S, van Laake LW, Doevendans PA, Mummery CL, Borlak J, Haverich A, et al: MicroRNAs in the human heart: A clue to fetal gene reprogramming in heart failure. Circulation 116: 258-267, 2007.

17. Grant JS, Morecroft I, Dempsie Y, van Rooij E, MacLean MR and Baker AH: Transient but not genetic loss of miR-451 is protective in the development of pulmonary arterial hypertension. Pulm Circ 3: 840-850, 2013.

18. Ma K, Zhao Q, Chen W, Zhang H,Li S, Pan X and Chen Q: Human lung microRNA profiling in pulmonary arterial hypertension secondary to congenital heart defect. Pediatr Pulmonol 50: 1214-1223, 2015. 
19. Wei C, Henderson H, Spradley C, Li L, Kim IK, Kumar S, Hong N, Arroliga AC and Gupta S: Circulating miRNAs as potential marker for pulmonary hypertension. PLoS One 8: e64396, 2013.

20. McLellan J, Heneghan CJ, Perera R, Clements AM, Glasziou PP Kearley KE, Pidduck N, Roberts NW, Tyndel S, Wright FL, et al B-type natriuretic peptide-guided treatment for heart failure. Cochrane Database Syst Rev: Dec 22, 2016 (Epub ahead of print). doi: 10.1002/14651858.CD008966.pub2.

21. Pruneda-Alvarez LG, Ruíz-Vera T, Ochoa-Martínez AC, Pérez-VázquezFJ,González Palomo AK, Ilizaliturri-HernándezCA and Pérez-Maldonado IN: Plasma asymmetric dimethylarginine (ADMA) levels in Mexican women exposed to polycyclic aromatic hydrocarbons (PAHs): A preliminary study. Sci Total Environ 572: $1195-1202,2016$.

22. Krowka MJ, Plevak DJ, Findlay JY, Rosen CB, Wiesner RH and Krom RA: Pulmonary hemodynamics and perioperative cardiopulmonary-related mortality in patients with portopulmonary hypertension undergoing liver transplantation. Liver Transpl 6: $443-450,2000$
23. Sr GY: Evaluation of acute hemodymamic effect of inhaled iloprost in pulmonary artery hypertension with right heart catheterization. Cardiovasc Revasc Med 10: 197-197, 2009.

24. Song XW, Zou LL, Cui L, Li SH, Qin YW, Zhao XX and Jing Q Plasma miR-451 echocardiography can be used as a reference for the diagnosis of pulmonary hypertension. Acta Pharmacol Sin 39: 1208-1216, 2018 .

25. Friedman WF: Proceedings of the National Heart, Lung, and Blood Institute Pediatric Cardiology Workshop: Pulmonary Hypertension. Pediatr Res 20: 811-824, 1986.

26. Schuijt MT, Blok IM,Zwinderman AH, van Riel AC, Schuuring MJ, de Winter RJ, Duijnhouwer AL, van Dijk AP, Mulder BJ and Bouma BJ: Mortality in pulmonary arterial hypertension due to congenital heart disease: Serial changes improve prognostication. Int J Cardiol 243: 449-453, 2017.

This work is licensed under a Creative Commons Attribution-NonCommercial-NoDerivatives 4.0 International (CC BY-NC-ND 4.0) License. 